\title{
On an Expression of Extraction Constants without the Interfacial Equilibrium-Potential Differences for the Extraction of Univalent and Divalent Metal Picrates by Crown Ethers into 1,2-Dichloroethane and Nitrobenzene
}

\author{
Yoshihiro Kudo*, Shoichi Katsuta \\ Graduate School of Science, Chiba University, Chiba, Japan \\ Email: iakudo@faculty.chiba-u.jp
}

Received 17 February 2015; accepted 25 March 2015; published 27 March 2015

Copyright (C) 2015 by authors and Scientific Research Publishing Inc.

This work is licensed under the Creative Commons Attribution International License (CC BY).

http://creativecommons.org/licenses/by/4.0/

\section{(c) (i) Open Access}

\begin{abstract}
An idea on interfacial equilibrium-potential differences $\left(\Delta \phi_{\mathrm{eq}}\right)$ which are generated for the extraction of univalent metal picrate (MPic) and divalent ones (MPic $)$ by crown ethers (L) into high-polar diluents was improved. These potentials were clarified with some experimental extractiondata reported before on the $\mathrm{M}=\mathrm{Ag}(\mathrm{I}), \mathrm{Ca}(\mathrm{II}), \mathrm{Sr}$ (II) and $\mathrm{Ba}(\mathrm{II})$ extraction with 18-crown-6 ether (18C6) and benzo-18C6 into 1,2-dichloroethane (DCE) and nitrobenzene (NB). Consequently, it was demonstrated that the $\Delta \phi_{\mathrm{eq}}$ values from the extraction-experimentally obtained $\log K_{\mathrm{D}, \mathrm{Pic}}$ ones are in agreement with or close to those calculated from charge balance equations in many cases, where the symbol, $K_{\mathrm{D}, \mathrm{Pic}}$, denotes an individual distribution constant of Pic ${ }^{-}$into the DCE or NB phase. Also, it was experimentally shown that extraction constants based on the overall extraction equilibria do not virtually contain the $\Delta \phi_{\mathrm{eq}}$ terms in their functional expressions.
\end{abstract}

\section{Keywords}

Extraction Constants, Distribution Constant of a Single Ion, Interfacial Equilibrium-Potential Differences, 1,2-Dichloroethane, Nitrobenzene, Metal Picrates, Crown Ethers

\footnotetext{
${ }^{*}$ Corresponding author.

How to cite this paper: Kudo, Y. and Katsuta, S. (2015) On an Expression of Extraction Constants without the Interfacial Equilibrium-Potential Differences for the Extraction of Univalent and Divalent Metal Picrates by Crown Ethers into 1,2-Dichloroethane and Nitrobenzene. American Journal of Analytical Chemistry, 6, 350-363. 


\section{Introduction}

Univalent and divalent metal picrates $\left(\mathrm{MPic}_{z}, z=1 \& 2\right)$, such as alkali and alkaline-earth metal ones, have been extracted by crown compounds (L) into the high-polar diluents, such as 1,2-dichloethane (DCE), dichloromethane and nitrobenzene (NB) [1]-[5]. In such high-polar diluents, an extracted ion-pair complex, MLPic dissociates $\mathrm{ML}^{{ }^{+}}$and $z \mathrm{Pic}^{-}$[1]-[3] [6]. In introducing these component equilibria in an extraction model, an individual distribution constant $\left(K_{\mathrm{D}, \mathrm{A}}\right)$ of $\mathrm{Pic}^{-}\left(=\mathrm{A}^{-}\right)$into the diluents has been determined extraction-experimentally [1]-[3] [7]. However, in spite of the limitation of the same $K_{\mathrm{D}, \mathrm{A}}$ definition and the same diluents, the thus-determined $K_{\mathrm{D} \text {,Pic }}$ values have differed from each other. For example, the $\log K_{\mathrm{D} \text {,Pic }}$ values were -0.94 [2] for the $\mathrm{PbPic}_{2}$ extraction with 18-crown-6 ether (18C6), -1.34 [7] for the $\mathrm{SrPic}_{2}$ one with benzo-18C6 (B18C6) into $\mathrm{NB},-2.4_{6}$ [3] for the AgPic one with benzo-15-crown-5 ether, -1.89 [2] for the $\mathrm{PbPic}_{2}$ one with $18 \mathrm{C} 6$ and $-4.3_{5}$ [6] for the $\mathrm{CdPic}_{2}$ one with 18C6 into DCE. Thus, their values have changed over experimental errors with combinations of $\mathrm{MPic}_{z}$ and $\mathrm{L}$.

To clarify a reason for such differences, the authors have applied the idea [8] of an interfacial potential difference $\left(\Delta \phi_{\mathrm{eq}}\right.$ ) at extraction equilibrium to an expression of $\log K_{\mathrm{D}, \mathrm{A}}$, namely $-f\left(\Delta \phi_{\mathrm{eq}}-\Delta \phi_{\mathrm{A}}^{0^{\prime}}\right) / 2.303$ [3] [6] [7], where the negative sign being in the front of $f$, which denotes $F / R T$, comes from the electrical charge of $\mathrm{A}^{-}$. In addition to this, extraction constants, $K_{\text {ex }}$ and $K_{\text {ex2 }}$, have been electrochemically expressed as

$z f\left(\Delta \phi_{\mathrm{eq}}-\Delta \phi_{k}^{0^{\prime}}\right) / 2.303$ at $k=\mathrm{ex} \pm$ and $z=1$ and at ex \pm , ex2 \pm and 2 [3] [7]. Here, $\Delta \phi_{\mathrm{A}}^{0^{\prime}}$ and $\Delta \phi_{k}^{0^{\prime}}$ refer to standard formal potentials for the single distribution of $\mathrm{A}^{-}$into the diluent or organic (o or org) phase and the formal potentials for the overall equilibrium, respectively. Also, $K_{\mathrm{ex}}$ and $K_{\mathrm{ex} 2 \pm}$ have been defined experimentally by extraction as $\left[\mathrm{MLA}^{+}\right]_{0}\left[\mathrm{~A}^{-}\right]_{0} /\left(\left[\mathrm{M}^{2+}\right][\mathrm{L}]_{0}\left[\mathrm{~A}^{-}\right]^{2}\right)$ [2] [7] or $\left[\mathrm{ML}^{+}\right]_{0}\left[\mathrm{~A}^{-}\right]_{0} /\left(\left[\mathrm{M}^{+}\right][\mathrm{L}]_{0}\left[\mathrm{~A}^{-}\right]\right)$[1]-[3] and $\left[\mathrm{ML}^{2+}\right]_{0}\left[\mathrm{~A}^{-}\right]_{0}^{2} /\left(\left[\mathrm{M}^{2+}\right][\mathrm{L}]_{0}\left[\mathrm{~A}^{-}\right]^{2}\right)[7]$, respectively.

On the other hand, from the thermodynamic points of view, these extraction constants are resolved into $K_{\mathrm{D}, \mathrm{M}}\left(K_{\mathrm{D}, \mathrm{A}}\right)^{2} K_{\mathrm{ML}, \text { org }} K_{1, \text { org }}\left(=K_{\mathrm{ex} \pm}\right)$ for $z=2[7], K_{\mathrm{D}, \mathrm{M}} K_{\mathrm{D}, \mathrm{A}} K_{\mathrm{ML}, \text { org }}$ for $1[3]$ and $K_{\mathrm{D}, \mathrm{M}}\left(K_{\mathrm{D}, \mathrm{A}}\right)^{2} K_{\mathrm{ML}, \text { org }}\left(=K_{\mathrm{ex} 2 \pm}\right)$ for $\mathrm{z}=2$ [7]. Here, the component equilibrium constants, $K_{\mathrm{ML}, \text { org }}$ (complex formation in the o phase) and $K_{1, \text { org }}$ (1st-step ion-pair formation in the o one), do not contain the $\Delta \phi_{\text {eq }}$ terms in their expressions, because the constants are of homogeneous systems that all species relevant to the reaction are present in the single o phase [3] [7]; namely no interface is involved in these processes. Similarly, the distribution constant of $\mathrm{M}^{z^{+}}$has been expressed with $K_{\mathrm{D}, \mathrm{M}}$ (see Equation (3) at $z=1$ in the Section 2.1) [3]. Therefore, since $K_{\mathrm{D}, \mathrm{M}}$ and $K_{\mathrm{D}, \mathrm{A}}$ are present in the $K_{\mathrm{D}, \mathrm{M}}\left(K_{\mathrm{D}, \mathrm{A}}\right)^{2}$ or $K_{\mathrm{D}, \mathrm{M}} K_{\mathrm{D}, \mathrm{A}}$ term, the both terms must cancel out mutually the $\Delta \phi_{\mathrm{eq}}$ ones. Thereby, the extraction constants virtually lose the $\Delta \phi_{\mathrm{eq}}$ terms on their functional expressions. Thus, the above expression, such as $\log K_{\mathrm{ex} \pm}=\mathrm{zf}\left(\Delta \phi_{\mathrm{eq}}-\Delta \phi_{\mathrm{ex} \pm}^{0}{ }^{\prime}\right) / 2.303$, has caused contradictions on the thermodynamic cycles [3] [7]. Furthermore, such contradictions can cause discrepancies in $\Delta \phi_{k}^{0^{\prime}}$ between experimentally-evaluated values and theoretically-reproduced ones [7].

In the present paper, in order to solve the above two contradictions, namely the differences of $K_{\mathrm{D}, \mathrm{A}}$ caused by experimental conditions of extraction and the contradiction based on the thermodynamic cycles [3] [7], we proposed another expression without $\Delta \phi_{\mathrm{eq}}$ of the extraction constants, $K_{\mathrm{ex} \pm}$ and $K_{\mathrm{ex} 2 \pm}$. In course of clarifying this expression, some experimentally-determined constants [3] [7], such as $K_{\text {ex }}$, an individual distribution constant $\left(K_{\mathrm{D}, \mathrm{ML}}\right)$ of the complex ion $\mathrm{ML}^{2+}$ into the $\mathrm{NB}$ phase and that of $\mathrm{AgL}^{+}$into DCE, were also reproduced by calculation. Here, the AgPic and $\mathrm{MPic}_{2}(\mathrm{M}=\mathrm{Ca}, \mathrm{Sr} \& \mathrm{Ba})$ extraction with L = 18C6 and/or B18C6 [3] [7] were employed as model systems. Also, a meaning of the $\Delta \phi_{\mathrm{eq}}$ values [3] [7] \& [8] which were calculated from the $\log K_{\mathrm{D}, \mathrm{A}}$ ones determined by the extraction experiments was discussed based on an electroneutrality-point of view [8] for the o phases. Moreover, the thus-obtained expressions for the extraction constants were applied to other types of extraction systems with $\mathrm{o}=$ DCE and NB. 


\section{Theory}

\section{1. $\Delta \phi_{\text {eq }}$ Values Derived from Charge Balance Equations for the o Phase}

(i) Case of the $M(I)$ extraction with $L$. For the extraction equilibrium,

$\mathrm{M}^{+}+\mathrm{L}_{\mathrm{o}}+\mathrm{A}^{-}\left(\rightleftharpoons \mathrm{MLA}_{\mathrm{o}}\right) \rightleftharpoons \mathrm{ML}_{\mathrm{o}}^{+}+\mathrm{A}_{\mathrm{o}}^{-}$, we can obtain from the extraction model (see Appendix I for more details) reported before the following charge-balance equation

$$
\left[\mathrm{M}^{+}\right]_{\mathrm{o}}+\left[\mathrm{ML}^{+}\right]_{\mathrm{o}}=\left[\mathrm{A}^{-}\right]_{\mathrm{o}}
$$

for the o phase. The concentrations of $\mathrm{M}^{+}$and $\mathrm{A}^{-}$in the o phase were modified as

$$
\left[\mathrm{M}^{+}\right] \exp \left\{f\left(\Delta \phi_{\mathrm{eq}}-\Delta \phi_{\mathrm{M}}^{0 \prime}\right)\right\}+\left[\mathrm{ML}^{+}\right]_{\mathrm{o}}=\left[\mathrm{A}^{-}\right] \exp \left\{-f\left(\Delta \phi_{\mathrm{eq}}-\Delta \phi_{\mathrm{A}}^{0^{\prime}}\right)\right\}
$$

by using electrochemical equations [6] [8] such as

$$
\Delta \phi_{\mathrm{eq}}=\Delta \phi_{\mathrm{M}}^{0 \prime}+f^{-1} \ln \left(\left[\mathrm{M}^{+}\right]_{\mathrm{o}} /\left[\mathrm{M}^{+}\right]\right)
$$

and

$$
\Delta \phi_{\mathrm{eq}}=\Delta \phi_{\mathrm{A}}^{0^{\prime}}-f^{-1} \ln \left(\left[\mathrm{A}^{-}\right]_{\mathrm{o}} /\left[\mathrm{A}^{-}\right]\right) ;
$$

see Appendix B in ref [6] for a detailed derivation from electrochemical potentials to this equation. Here, $\Delta \phi_{j}^{0^{\prime}}$ and $[j]_{0} /[j]$ denote a standard formal potential of species $j\{=\mathrm{M}(\mathrm{I}), \mathrm{A}(-\mathrm{I}) \& \mathrm{ML}(\mathrm{I})$; see the introduction and section 3.3\} and the individual distribution constant $\left(K_{\mathrm{D}, j}\right)$ of $j$ between the two phases, respectively. At least, the $\Delta \phi_{j}^{0^{\prime}} \quad$ values are available from references for $\mathrm{M}=\mathrm{Ag}(\mathrm{I})$ [9], $\mathrm{Ca}(\mathrm{II})$ [10], $\mathrm{Sr}(\mathrm{II})$ [10] and $\mathrm{Ba}(\mathrm{II})$ [10] and $\mathrm{A}=$ Pic(-I) [11] into the DCE and NB phases. Additionally, the

$\log K_{\mathrm{D}, \mathrm{A}}\left\{=\log \left(\left[\mathrm{A}^{-}\right]_{0} /\left[\mathrm{A}^{-}\right]\right)=2.303^{-1} \ln \left(\left[\mathrm{A}^{-}\right]_{0} /\left[\mathrm{A}^{-}\right]\right)\right\}$values have been determined extraction-experimentally [1]-[3] [6] [7]; see Appendix II for the $K_{\mathrm{D}, \mathrm{A}}$ determination. Defining as $\exp \left(f \Delta \phi_{\mathrm{eq}}\right)=x$ and then rearranging Equation (2), we can easily obtain

$$
x=\left(\sqrt{b^{2}-4 a c}-b\right) / 2 a(>0)
$$

with

$$
\begin{gathered}
a=\left[\mathrm{M}^{+}\right] \exp \left(-f \Delta \phi_{\mathrm{M}}^{0^{\prime}}\right), \\
b=\left[\mathrm{ML}^{+}\right]_{\mathrm{o}}
\end{gathered}
$$

and

$$
c=-\left[\mathrm{A}^{-}\right] \exp \left(f \Delta \phi_{\mathrm{A}}^{0^{\prime}}\right)
$$

Accordingly, the following equation is derived.

$$
\Delta \phi_{\mathrm{eq}}=f^{-1} \ln x=0.05916 \log x(\mathrm{~V} \text { unit at } 298 \mathrm{~K})
$$

Hence, if the $\left[\mathrm{M}^{+}\right],\left[\mathrm{ML}^{+}\right]_{\mathrm{o}}$ and $\left[\mathrm{A}^{-}\right]$values are determined experimentally, then we can obtain the $\Delta \phi_{\mathrm{eq}}$ values from Equation (6) immediately; the $\left[\mathrm{ML}^{+}\right]_{0}$ values were calculated here from the relation $\left[\mathrm{ML}^{+}\right]_{\mathrm{o}}=\left(K_{\mathrm{ex}}^{\mathrm{mix}}-K_{\mathrm{ex}}\right)\left[\mathrm{M}^{+}\right][\mathrm{L}]_{\mathrm{o}}\left[\mathrm{A}^{-}\right](>0)$ with $K_{\mathrm{ex}}^{\mathrm{mix}}=\{$ total concentration of analyzed $\mathrm{M}(\mathrm{I})$ in the o phase $\} /\left(\left[\mathrm{M}^{+}\right][\mathrm{L}]_{0}\left[\mathrm{~A}^{-}\right]\right)$(see Appendix II for more detail) and $K_{\mathrm{ex}}=[\mathrm{MLA}]_{\mathrm{o}} /\left(\left[\mathrm{M}^{+}\right][\mathrm{L}]_{0}\left[\mathrm{~A}^{-}\right]\right)$. The data of $\left[\mathrm{ML}^{+}\right]_{0} \leq 0$ were neglected in a further computation.

(ii) Case of the $\mathrm{M}(\mathrm{II})$ extraction with L. Similarly, we can consider the following stepwise extraction-equilibria [6] [12] at the same time: $\mathrm{M}^{2+}+\mathrm{L}_{\mathrm{o}}+2 \mathrm{~A}^{-}\left(\rightleftharpoons \mathrm{MLA}_{2, \mathrm{o}}\right) \rightleftharpoons \mathrm{MLA}_{\mathrm{o}}^{+}+\mathrm{A}_{\mathrm{o}}^{-} \rightleftharpoons \mathrm{ML}_{\mathrm{o}}^{2+}+2 \mathrm{~A}_{\mathrm{o}}^{-}$(see Appendix I 
for a basic extraction model and Appendix II for the $K_{\mathrm{D}, \mathrm{A}}$ determination). Therefore, the charge balance equation for the o phase becomes

$$
2\left[\mathrm{M}^{2+}\right]_{0}+2\left[\mathrm{ML}^{2+}\right]_{0}+\left[\mathrm{MLA}^{+}\right]_{0}=\left[\mathrm{A}^{-}\right]_{0} .
$$

As described above, this equation was modified to [8]

$$
\begin{aligned}
& 2\left[\mathrm{M}^{2+}\right] \exp \left\{2 f\left(\Delta \phi_{\mathrm{eq}}-\Delta \phi_{\mathrm{M}}^{0^{\prime}}\right)\right\}+2\left[\mathrm{ML}^{2+}\right] \exp \left\{2 f\left(\Delta \phi_{\mathrm{eq}}-\Delta \phi_{\mathrm{ML}}^{0}{ }^{\prime}\right)\right\}+\left[\mathrm{MLA}^{+}\right]_{0} \\
& =\left[\mathrm{A}^{-}\right] \exp \left\{-f\left(\Delta \phi_{\mathrm{eq}}-\Delta \phi_{\mathrm{A}}^{0^{\prime}}\right)\right\} .
\end{aligned}
$$

Defining as $\exp \left(f \Delta \phi_{\mathrm{eq}}\right)=x$ and then rearranging Equation (8), we easily obtain the cubic equation

$$
a^{\prime} x^{3}+b^{\prime} x+c^{\prime}=0
$$

with

$$
\begin{gathered}
a^{\prime}=2\left[\mathrm{M}^{2+}\right] \exp \left(-2 f \Delta \phi_{\mathrm{M}}^{0 \prime}\right)+2\left[\mathrm{ML}^{2+}\right] \exp \left(-2 f \Delta \phi_{\mathrm{ML}}^{0{ }^{\prime}}\right), \\
b^{\prime}=\left[\mathrm{MLA}^{+}\right]_{0}
\end{gathered}
$$

and

$$
c^{\prime}=-\left[\mathrm{A}^{-}\right] \exp \left(f \Delta \phi_{\mathrm{A}}^{0^{\prime}}\right)
$$

We can exactly solve this equation for $x$ based on the mathematical formula [13]. Its real solution is

$$
x=\left\{-(q / 2)+\sqrt{\left(q^{2} / 4\right)+\left(p^{3} / 27\right)}\right\}^{1 / 3}+\left\{-(q / 2)-\sqrt{\left(q^{2} / 4\right)+\left(p^{3} / 27\right)}\right\}^{1 / 3},
$$

where $p=b^{\prime} / a^{\prime}$ and $q=c^{\prime} / a^{\prime}$. Therefore, we can similarly obtain the $\Delta \phi_{\mathrm{eq}}$ value from the combination of Equations (6) and (10).

The $b^{\prime}$ values were evaluated from the relation, $r_{+} \sum\left[\mathrm{MLA}_{N}^{(2-N)+}\right]_{0}$ with $N=1$ and 2, where $r_{+}=\left[\mathrm{MLA}^{+}\right]_{0} /\left(\left[\mathrm{MLA}^{+}\right]_{0}+\left[\mathrm{MLA}_{2}\right]_{0}\right)$

$\left(\approx\left(K_{\text {ex }}\left[\mathrm{M}^{2+}\right][\mathrm{L}]_{0}\right)^{1 / 2}\left[\mathrm{~A}^{-}\right] /\left\{\left(K_{\text {ex }}\left[\mathrm{M}^{2+}\right][\mathrm{L}]_{0}\right)^{1 / 2}\left[\mathrm{~A}^{-}\right]+K_{\text {ex }}\left[\mathrm{M}^{2+}\right][\mathrm{L}]_{0}\left[\mathrm{~A}^{-}\right]^{2}\right\}\right.$ under the condition of

$\left.\left[\mathrm{MLA}^{+}\right]_{0} \approx\left[\mathrm{A}^{-}\right]_{0}[7]\right)$. The $\sum\left[\mathrm{MLA}_{N}^{(2-N)+}\right]_{0}$ values were directly determined by AAS measurements in the extraction experiments [2] [7] and also we were able to calculate the other values in $r_{+}$from the experimental data [7].

\subsection{On Expressions of the Extraction Constants without $\Delta \phi_{\mathrm{eq}}$}

According to previous papers, the two of the three extraction constants have been defined as $\log K_{\mathrm{ex} \pm}=f\left(\Delta \phi_{\mathrm{eq}}-\Delta \phi_{\mathrm{ex} \pm}^{0}{ }^{\prime}\right) / 2.303=\left(f \Delta \phi_{\mathrm{eq}} / 2.303+\log K_{\mathrm{ex} \pm}^{\mathrm{S}}\right)$ for the $\mathrm{M}^{\mathrm{I}} \mathrm{A}-\mathrm{L}$ extraction system [3] and $\log K_{\text {ex } \pm}=f\left(\Delta \phi_{\text {eq }}-\Delta \phi_{\text {ex }}^{0}{ }^{\prime}\right) / 2.303 \quad$ and $\quad \log K_{\text {ex } 2 \pm}=2 f\left(\Delta \phi_{\text {eq }}-\Delta \phi_{\text {ex } 2 \pm}^{0}\right) / 2.303=\left(2 f \Delta \phi_{\text {eq }} / 2.303+\log K_{\text {ex2 }}^{\mathrm{S}}\right)$ for the $\mathrm{M}^{\mathrm{II}} \mathrm{A}_{2}$-L extraction one [7]. Here, $\log K_{\mathrm{ex} \pm}$ (or $\log K_{\mathrm{ex} 2 \pm}$ ) equals $\log K_{\mathrm{ex} \pm}^{\mathrm{S}}$ (or $\log K_{\mathrm{ex} 2 \pm}^{\mathrm{S}}$ ) at $\Delta \phi_{\mathrm{eq}}=0 \mathrm{~V}$. These two kinds of extraction constants contain the $\Delta \phi_{\mathrm{eq}}$ terms as parameters in their functional expressions[3] [7]. On the other hand, $\log K_{\mathrm{ex}}$ has been expressed as $-f \Delta \phi_{\mathrm{ex}}^{0 \prime} / 2.303$ or $-2 f \Delta \phi_{\mathrm{ex}}^{0 \prime} / 2.303$ without $\Delta \phi_{\mathrm{eq}}$ and spontaneously became an expression electrochemically-standardized at $\Delta \phi_{\mathrm{eq}}=0 \mathrm{~V}$ [3] [7].

In the above functions, some contradictions have been observed in the former cases: see Appendix in ref. [7]. As an example similar to that described in the introduction, the relation, 
$\log K_{\mathrm{ex}}-\log K_{\mathrm{ex} \pm}=\log K_{2, \mathrm{org}}\left\{=\log \left(\left[\mathrm{MLA}_{2}\right]_{\mathrm{o}} /\left[\mathrm{MLA}^{+}\right]_{0}\left[\mathrm{~A}^{-}\right]_{0}\right)\right\}$, must give a function without $\Delta \phi_{\mathrm{eq}}$, because the resulting component equilibrium-constant $K_{2, \text { org }}$ does not relate with $\Delta \phi_{\mathrm{eq}}$ [7]; namely $K_{2, \text { org }}$ and $K_{\mathrm{ex}}$ are the constants at $\Delta \phi_{\mathrm{eq}}=0 \mathrm{~V}$. However, using the above definition [3] [7], the same term, $\log K_{\mathrm{ex}}-\log K_{\mathrm{ex} \pm}$, becomes $\log K_{\mathrm{ex}}^{\mathrm{S}}-\log K_{\mathrm{ex} \pm}^{\mathrm{S}}=-f \Delta \phi_{\mathrm{eq}} / 2.303$ and then the $\Delta \phi_{\mathrm{eq}}$ term does not disappear, where

$\log K_{\mathrm{ex}}^{\mathrm{S}}\left(=\log K_{\mathrm{ex}}\right)=-2 f \Delta \phi_{\mathrm{ex}}^{0 \prime} / 2.303$ and $\log K_{\mathrm{ex} \pm}^{\mathrm{S}}=-2 f \Delta \phi_{\mathrm{ex} \pm}^{0}{ }^{\prime} / 2.303$. The same is also true of the result of $\log K_{\text {ex } \pm}-\log K_{\text {ex } 2 \pm}=\left(\log K_{\text {ex }}^{\mathrm{S}}-\log K_{\text {ex } 2 \pm}^{\mathrm{s}}-f \Delta \phi_{\text {eq }} / 2.303\right)=\log K_{1, \text { org }}$ which is defined as

$\log \left(\left[\mathrm{MLA}^{+}\right]_{0} /\left[\mathrm{ML}^{2+}\right]_{0}\left[\mathrm{~A}^{-}\right]_{0}\right)$. These two facts obviously have the contradiction with respect to $\Delta \phi_{\mathrm{eq}}$.

In order to cancel such contradictions, we assume here that the two extraction constants are functions without $\Delta \phi_{\text {eq }}$, as well as that of $K_{\text {ex }}$ [3] [7]. Accordingly, the constants are defined as

and

$$
\log K_{\mathrm{ex} \pm}=\log K_{\mathrm{ex \pm}}^{\mathrm{S}}=-f \Delta \phi_{\mathrm{ex} \pm}^{0}{ }^{\prime} / 2.303
$$

$$
\log K_{\mathrm{ex} 2 \pm}=\log K_{\mathrm{ex} 2 \pm}^{\mathrm{S}}=-2 f \Delta \phi_{\mathrm{ex} 2 \pm}^{0}{ }^{\prime} / 2.303 .
$$

That is, by our traditional sense, it is proposed here that complicated equilibrium constants, such as $K_{\mathrm{ex}}, K_{\mathrm{ex} \pm}$ and $K_{\text {ex2t }}$, do not contain the $\Delta \phi_{\text {eq }}$ terms in their functions. This means that these constants are ordinarily defined without $\Delta \phi_{\mathrm{eq}}$ or under the condition of $\Delta \phi_{\mathrm{eq}}=0 \mathrm{~V}$ and thereby are electrochemically-standardized as $K_{\mathrm{ex} \pm}^{\mathrm{S}}$ and $K_{\text {ex } 2 \pm}^{\mathrm{S}}$ [3] [7]. Table 1 lists new (or traditional) expressions of such extraction constants composed of some component equilibrium constants based on thermodynamic cycles.

The relations in Table 1 shows that the individual distribution process of $\mathrm{A}^{-}$[12] cancels out that of a cation [14], such as $\mathrm{M}^{+}, \mathrm{R}_{4} \mathrm{~N}^{+}, \mathrm{M}^{2+}$ and $\mathrm{ML}^{2+}$, in $\Delta \phi_{\text {eq }}$. As an example, the thermodynamic relation for $\mathrm{M}(\mathrm{II})$

$$
\log K_{\mathrm{ex} \pm}=\log K_{\mathrm{D}, \mathrm{M}}+2 \log K_{\mathrm{D}, \mathrm{A}}+\log K_{\mathrm{ML}, \text { org }}+\log K_{1, \mathrm{org}}
$$

can be rearranged into

$$
\begin{aligned}
& -f \Delta \phi_{\mathrm{ex} \pm}^{0}{ }^{\prime}=2 f\left(\Delta \phi_{\mathrm{eq}}-\Delta \phi_{\mathrm{M}}^{0 \prime}\right)-2 f\left(\Delta \phi_{\mathrm{eq}}-\Delta \phi_{\mathrm{A}}^{0^{\prime}}\right)-2 f \Delta \phi_{\mathrm{ML}, \mathrm{org}}^{0}-f \Delta \phi_{1, \mathrm{org}}^{0}{ }^{\prime} \\
& =-2 f \Delta \phi_{\mathrm{M}}^{0 \prime}+2 f \Delta \phi_{\mathrm{A}}^{0{ }^{\prime}}-2 f \Delta \phi_{\mathrm{ML}, \mathrm{org}}^{0}-f \Delta \phi_{1, \mathrm{org}}^{0} .
\end{aligned}
$$

\begin{tabular}{|c|c|}
\hline Overall equilibrium \& Its cycle ${ }^{b}$ & Relation \\
\hline $\begin{array}{l}\mathrm{M}^{+}+\mathrm{L}_{\mathrm{o}}+\mathrm{A}^{-} \rightleftharpoons \mathrm{ML}_{\mathrm{o}}^{+}+\mathrm{A}_{\mathrm{o}}^{-} \\
\text {(a) } K_{\mathrm{ex} \pm}=K_{\mathrm{D}, \mathrm{M}} K_{\mathrm{D}, \mathrm{A}} K_{\mathrm{ML}, \mathrm{org}}{ }^{\mathrm{c}} \\
\text { (b) } K_{\mathrm{ex} \pm}=K_{\mathrm{D}, \mathrm{ML}} K_{\mathrm{D}, \mathrm{A}} K_{\mathrm{ML}} / K_{\mathrm{D}, \mathrm{L}}\end{array}$ & $\begin{array}{c}\text { (a) } \log K_{\mathrm{ex} \pm}=\log K_{\mathrm{D}, \mathrm{M}}+\log K_{\mathrm{D}, \mathrm{A}}+\log K_{\mathrm{ML}, \mathrm{org}} \\
\text { or } \Delta \phi_{\mathrm{ex} \pm}^{0 \prime}=\Delta \phi_{\mathrm{M}}^{0 \prime}-\Delta \phi_{\mathrm{A}}^{0 \prime}+\Delta \phi_{\mathrm{ML}, \mathrm{org}}^{\prime} \\
\text { (b) } \log K_{\mathrm{ex} \pm}=\log K_{\mathrm{D}, \mathrm{ML}}+\log K_{\mathrm{D}, \mathrm{A}}+\log K_{\mathrm{ML}}-\log K_{\mathrm{D}, \mathrm{L}} \text { or } \\
\Delta \phi_{\mathrm{ex} \pm}^{0 \prime}=\Delta \phi_{\mathrm{ML}}^{0}{ }^{\prime}-\Delta \phi_{\mathrm{A}}^{0 \prime}+\Delta \phi_{\mathrm{ML}, \mathrm{w}}^{0}-\Delta \phi_{\mathrm{L}}^{0 \prime}\end{array}$ \\
\hline $\begin{array}{l}\mathrm{M}^{2+}+\mathrm{L}_{\mathrm{o}}+2 \mathrm{~A}^{-} \rightleftharpoons \mathrm{MLA}_{\mathrm{o}}^{+}+\mathrm{A}_{\mathrm{o}}^{-} \\
\text {(c) } K_{\mathrm{ex \pm}}=K_{\mathrm{D}, \mathrm{M}}\left(K_{\mathrm{D}, \mathrm{A}}\right)^{2} K_{\mathrm{ML}, \mathrm{org}} K_{\mathrm{L}, \mathrm{org}} \mathrm{d}\end{array}$ & $\begin{array}{c}\text { (c) } \log K_{\mathrm{ex \pm}}=\log K_{\mathrm{D}, \mathrm{M}}+2 \log K_{\mathrm{D}, \mathrm{A}}+\log K_{\mathrm{ML}, \text { org }}+\log K_{\mathrm{1}, \mathrm{org}} \text { or } \\
\Delta \phi_{\mathrm{ex} \pm}^{0 \prime}=2 \Delta \phi_{\mathrm{M}}^{0 \prime}-2 \Delta \phi_{\mathrm{A}}^{0 \prime}+2 \Delta \phi_{\mathrm{ML}, \mathrm{org}}^{0}+\Delta \phi_{1, \mathrm{org}}^{0}{ }^{\prime}\end{array}$ \\
\hline (d) $K_{\text {ex }}=K_{\mathrm{D}, \mathrm{ML}}\left(K_{\mathrm{D}, \mathrm{A}}\right)^{2} K_{\mathrm{ML}} K_{1, \mathrm{org}} / K_{\mathrm{D}, \mathrm{L}}^{\mathrm{d}}$ & 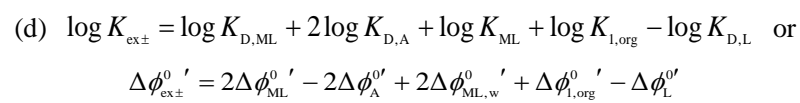 \\
\hline $\begin{array}{l}\mathrm{M}^{2+}+\mathrm{L}_{\mathrm{o}}+2 \mathrm{~A}^{-} \rightleftharpoons \mathrm{ML}_{\mathrm{o}}^{2+}+2 \mathrm{~A}_{\mathrm{o}}^{-} \\
\text {(e) } K_{\mathrm{ex} 2 \pm}=K_{\mathrm{D}, \mathrm{M}}\left(K_{\mathrm{D}, \mathrm{A}}\right)^{2} K_{\mathrm{ML}, \mathrm{org}}{ }^{\mathrm{d}}\end{array}$ & $\begin{array}{c}\text { (e) } \log K_{\mathrm{ex} 2 \pm}=\log K_{\mathrm{D}, \mathrm{M}}+2 \log K_{\mathrm{D}, \mathrm{A}}+\log K_{\mathrm{ML}, \mathrm{org}} \text { or } \\
\Delta \phi_{\mathrm{ex} 2 \pm}^{0}{ }^{\prime}=\Delta \phi_{\mathrm{M}}^{0^{\prime}}-\Delta \phi_{\mathrm{A}}^{0^{\prime}}+\Delta \phi_{\mathrm{ML}, \text { org }}^{0}\end{array}$ \\
\hline (f) $K_{\mathrm{ex} 2 \pm}=K_{\mathrm{D}, \mathrm{ML}}\left(K_{\mathrm{D}, \mathrm{A}}\right)^{2} K_{\mathrm{ML}} / K_{\mathrm{D}, \mathrm{L}}$ & 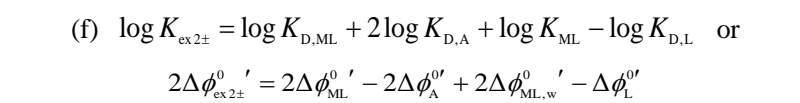 \\
\hline
\end{tabular}

Table 1. Relations between $K_{\mathrm{ex} \pm}$ or $K_{\mathrm{ex} 2 \pm}$ and its component equilibrium constants and their corresponding $\Delta \phi_{k}^{0^{\prime}}$ values ${ }^{\mathrm{a}}$.

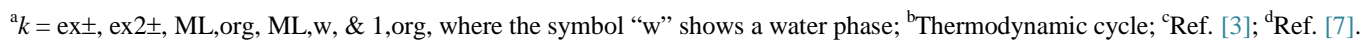


Therefore, the relation (c) in Table 1 is immediately obtained. From Equations (2) and (8), one should obviously see that $\Delta \phi_{\mathrm{eq}}$ of $K_{\mathrm{D}, \mathrm{M}}$ equals that of $K_{\mathrm{D}, \mathrm{A}}$ in the extraction system of Equation (13). Also, we can rewrite Equation (13) to

$$
\log K_{\mathrm{ex} \pm}=\log K_{\mathrm{D}, \mathrm{M}}^{\mathrm{S}}+2 \log K_{\mathrm{D}, \mathrm{A}}^{\mathrm{S}}+\log K_{\mathrm{ML}, \text { org }}+\log K_{1, \mathrm{org}}=\log K_{\mathrm{ex} \pm}^{\mathrm{S}}
$$

Consequently, Equation (14) or (13) does not contain the $\Delta \phi_{\mathrm{eq}}$ term and is virtually expressed with only the standard formal potentials (at $\Delta \phi_{\mathrm{eq}}=0 \mathrm{~V}$ ) as Equation (13a). The thermodynamic relations are also satisfied with the expressions such as Equations (11) and (12). The same is true of the other relations in Table 1.

\section{Results and Discussion}

\subsection{On a Meaning of $\Delta \phi_{\text {eq }}$ Estimated from $\log K_{\mathrm{D}, \mathrm{A}}$}

Table 2(a) lists fundamental data [3] for the extraction of AgPic by B18C6 into DCE. The $\Delta \phi_{\text {eq }}$ values were calculated from Equation (4) and the experimental $\log K_{\mathrm{D} \text {,Pic }}$ values in Table 2(a).

Here, $f \Delta \phi_{\text {Pic }}^{0}{ }^{\prime} / 2.303\left(=\Delta \phi_{\text {Pic }}^{0} / 0.05916=\log K_{\text {D,Pic }}^{\mathrm{S}}\right)=-1.01_{1}$ [11] at $298 \mathrm{~K}$ was employed in the calculation.

Table 2. (a) Fundamental data for the extraction of AgPic by B18C6 into DCE at $298 \mathrm{~K}$; (b) Evaluated $\Delta \phi_{\mathrm{eq}}$ values; (c) Reproduced $\log K_{\mathrm{ex} \pm}$ values; (d) Evaluated $\log K_{\mathrm{D}, \mathrm{AgL}}^{\mathrm{S}}$ and reproduced $\log K_{\mathrm{D}, \mathrm{AgL}}$ values.

(a)

\begin{tabular}{|c|c|c|c|c|c|c|}
\hline Data no. & $\log K_{\text {ex }}$ & $\log K_{\mathrm{ex} \pm}$ & $\log K_{\mathrm{D}, \mathrm{A}}$ & $\begin{array}{l}\log K_{\mathrm{ML}, \mathrm{DCE}}{ }^{\mathrm{a}} \\
\left(I_{\mathrm{DCE}}^{\mathrm{c}} / 10^{-5}\right)\end{array}$ & $\log K_{1, \mathrm{DCE}}{ }^{\mathrm{b}}$ & $\log K_{\mathrm{D}, \mathrm{ML}}$ \\
\hline $1 \mathrm{~A}^{\mathrm{d}}$ & 5.55 & $0.17^{\mathrm{e}} \pm 0.03,-0.5_{1}$ & -2.70 & $5.68^{f}(0.64)$ & $5.38^{\mathrm{e}}, 6.0_{5}$ & $3.05^{\mathrm{f}}$ \\
\hline $1 \mathrm{~B}^{\mathrm{g}}$ & $5.17 \pm 0.01$ & $0.25 \pm 0.09$ & $-2.33 \pm 0.03$ & $5.76(0.40)$ & 4.92 & 2.76 \\
\hline $1 \mathrm{C}^{\mathrm{g}}$ & $5.336 \pm 0.004$ & $0.5_{1} \pm 0.1_{0}$ & $-2.60 \pm 0.05$ & $6.03(1.1)$ & 4.82 & 3.3 \\
\hline $2^{\mathrm{g}}$ & $5.07 \pm 0.01$ & $-0.13 \pm 0.09$ & $-1.68 \pm 0.02$ & $5.38(0.55)$ & 5.20 & 1.73 \\
\hline
\end{tabular}

${ }^{\mathrm{a}}$ Values calculated from $\log K_{\mathrm{ML}, \mathrm{DCF}}=\log K_{\mathrm{ex \perp}}-\log K_{\mathrm{D}, \mathrm{A}}-\left(\Delta \phi_{\mathrm{eq}} / 0.05916+\log K_{\mathrm{D}, \mathrm{M}}^{\mathrm{s}}\right)$ at $298 \mathrm{~K} ;{ }^{\mathrm{b}}$ Values calculated from

$\log K_{1, \mathrm{DCE}}=\log K_{\mathrm{ex}}-\log K_{\mathrm{ex} \pm}$; ${ }^{\mathrm{c}} \mathrm{Unit}$ : mol dm ${ }^{-3}$; ${ }^{\mathrm{d}} \mathrm{Ref}$. [3]; ${ }^{\mathrm{e}}$ Values re-calculated from the same data as that reported before. See ref. [3]; ${ }^{\mathrm{f}}$ Additionally determined values which were calculated from the same data as that reported before. See ref. [3]; ${ }^{\mathrm{g}}$ Data obtained from additional extraction experiments. Experimental conditions and data analyses are essentially the same as those reported on ref. [3]. For only the data no. 2, the w phases were prepared with about $0.1 \mathrm{~mol} \mathrm{dm}^{-3} \mathrm{HNO}_{3}$.

(b)

\begin{tabular}{ccccc}
\hline & Data no. 1A & $1 \mathrm{~B}$ & $1 \mathrm{C}$ & 2 \\
\hline$\Delta \phi_{\mathrm{eq}}^{(\mathrm{P} 1)} / \mathrm{V}$ & 0.10 & 0.078 & 0.094 & 0.040 \\
$\Delta \phi_{\mathrm{eq}, \mathrm{av}}^{(\mathrm{P2})} / \mathrm{V}$ & $0.09_{3} \pm 0.01_{3}$ & $0.07_{4} \pm 0.01_{2}$ & $0.08_{9} \pm 0.01_{2}$ & $0.040 \pm 0.005$ \\
\hline
\end{tabular}

(c)

\begin{tabular}{|c|c|c|c|c|}
\hline & Data no. $1 \mathrm{~A}$ & $1 \mathrm{~B}$ & $1 \mathrm{C}$ & 2 \\
\hline $\log K_{\mathrm{ex} \pm}^{(\mathrm{K} 5)} *$ & 0.17 & 0.25 & 0.52 & -0.13 \\
\hline
\end{tabular}

${ }^{*} \log K_{\mathrm{ext}}^{(\mathrm{K} 5)}=\log K_{\mathrm{D}, \mathrm{Ag}}^{\mathrm{s}}+\log K_{\mathrm{D}, \mathrm{Pic}}^{\mathrm{s}}+\log K_{\mathrm{Ag} \mathrm{gL}, \mathrm{DCE}}^{(\mathrm{Tadble(a)}}$.

(d)

\begin{tabular}{ccccc}
\hline & Data no. $1 \mathrm{~A}$ & $1 \mathrm{~B}$ & $1 \mathrm{C}$ & 2 \\
\hline $\log K_{\mathrm{D}, \mathrm{AgL}}^{\mathrm{S(K6)}} *$ & 1.36 & 1.44 & 1.7 & 1.06 \\
$\log K_{\mathrm{D}, \mathrm{AgL}}^{(\mathrm{K})} \S$ & 2.94 & 2.70 & 3.2 & 1.74 \\
\hline
\end{tabular}

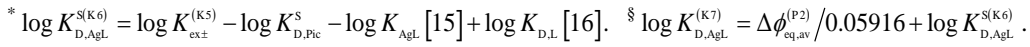


Also, we estimated $\Delta \phi_{\mathrm{eq}, \mathrm{av}}$ from Equation (6) with Equation (5), where $\Delta \phi_{\mathrm{eq}, \mathrm{av}}$ denotes an average value for each run.

The both values, expressed as $\Delta \phi_{\mathrm{eq}}^{(\mathrm{P} 1)} \& \Delta \phi_{\mathrm{eq}, \mathrm{av}}^{(\mathrm{P} 2)}$ in Table 2(b), agreed well within experimental errors.

Average $I$ values of the extraction systems in Table 2(a) were $0.0036 \mathrm{~mol} \cdot \mathrm{dm}^{-3}$ for the no. $1 \mathrm{~A}$ [3], 0.0028 for $1 \mathrm{~B}, 0.0027$ for $1 \mathrm{C}$ and 0.097 for 2; $I$ denotes the ionic strength of the water phase in the extraction. Except for the data no. 2, we can handle other three data on the average, because experimental conditions [3] of the data are essentially the same (see the footnote $\mathrm{g}$ in Table 2(a) for no. 2). So the following values were obtained at $298 \mathrm{~K}$ and $\mathrm{L}=\mathrm{B} 18 \mathrm{C} 6: \log K_{\mathrm{ex}}=0.3_{1} \pm 0.1_{4}$ and $\log K_{\mathrm{D}, \mathrm{Pic}}=-2.54 \pm 0.07$;

$\log K_{\mathrm{AgL}, \mathrm{DCE}}\left\{=\log \left(\left[\mathrm{AgL}^{+}\right]_{\mathrm{DCE}} /\left[\mathrm{Ag}^{+}\right]_{\mathrm{DCE}}[\mathrm{L}]_{\mathrm{DCE}}\right)\right\}=5.7_{1} \pm 0.2_{3}$ in the $I_{\mathrm{DCE}}$ range of $(0.40-1.1) \times 10^{-5}$ mol. $\mathrm{dm}^{-3}$ (see the data in Table 2(a)) and $\log K_{1, \mathrm{DCE}}\left\{=\log \left([\mathrm{AgLPic}]_{\mathrm{DCE}} /\left[\mathrm{AgL}^{+}\right]_{\mathrm{DCE}}\left[\mathrm{PiC}^{-}\right]_{\mathrm{DCE}}\right)\right\}=5.0_{8} \pm 0.2_{2}$ in the same $I_{\mathrm{DCE}}$ range. The symbol, $I_{\mathrm{DCE}}$, refers to the average ionic strength of the DCE phase; the same is true of $I_{\mathrm{NB}}$ (see Table 3).

Table 3(a) summarizes the fundamental data [7] for the extraction of $\mathrm{MPic}_{2}(\mathrm{M}=\mathrm{Ca}$, Sr \& Ba) by $18 \mathrm{C6}$ and B18C6 into NB.

The $\Delta \phi_{\mathrm{eq}}$ values were calculated from Equation (4) with the $\log K_{\mathrm{D}, \mathrm{Pic}}$ values in Table 3(a) and the $\Delta \phi_{\mathrm{Pic}}^{0}{ }^{\prime} / 0.05916\left(=\log K_{\mathrm{D}, \mathrm{Pic}}^{\mathrm{S}}\right)=0.05$ [11] ones reported previously. From Equation (6) with Equation (10), the $\Delta \phi_{\text {eq,av }}$ values were estimated in the same manner. The above findings are listed in Table 3(b).

For the 18C6 extraction systems, the $\Delta \phi_{\mathrm{eq}}^{(\mathrm{P} 3)}$ values obtained from Equation (4) are close to the $\Delta \phi_{\mathrm{eq}, \mathrm{av}}^{(\mathrm{P})}$ ones from Equation (6) with Equation (10). On the other hand, the former values are larger than the latter ones for the B18C6 extraction systems.

Except for the $\Delta \phi_{\mathrm{eq}}^{(\mathrm{P} 3)}$ and $\Delta \phi_{\mathrm{eq}, \mathrm{av}}^{(\mathrm{P} 4)}$ values of the B18C6 systems, the above results indicate that the interfacial equilibrium-potential differences, $\Delta \phi_{\text {eq }}$, based on Equation (4) are essentially the same as those based on Equation (6). The differences between $\Delta \phi_{\mathrm{eq}}^{(\mathrm{P} 3)}$ and $\Delta \phi_{\mathrm{eq}, \mathrm{av}}^{(\mathrm{P} 4)}$ for the B18C6 systems can be due to those in the charge balance equation between extraction experiments (see Appendix II) and electrochemical (or theoretical) treatments, namely $\left[\mathrm{MLPic}^{+}\right]_{\mathrm{NB}} \approx\left[\mathrm{Pic}^{-}\right]_{\mathrm{NB}}$ [7] and Equation (7) or (8). In other words, the condition of $2\left[\mathrm{M}^{2+}\right]_{\mathrm{NB}}+2\left[\mathrm{ML}^{2+}\right]_{\mathrm{NB}} \ll\left[\mathrm{MLPic}^{+}\right]_{\mathrm{NB}}$ cannot be satisfied in the B18C6 systems. For example, an average value of $2\left[\mathrm{BaL}^{2+}\right]_{\mathrm{NB}} /\left[\mathrm{BaLPic}^{+}\right]_{\mathrm{NB}}$ was $0.1_{2}$ for $\mathrm{L}=\mathrm{B} 18 \mathrm{C} 6$, while that was $0.02_{9}$ for $18 \mathrm{C} 6$; these values were the maximum of the B18C6- and 18C6-M(II) extraction systems. Practically, the $\Delta \phi_{\mathrm{eq}, \mathrm{av}}^{(\mathrm{P} 4)}$ values based on Equation (7) or (8) must be more accurate than the $\Delta \phi_{\mathrm{eq}}^{(\mathrm{P} 3)}$ ones.

On the basis of the above facts, $\Delta \phi_{\mathrm{eq}}^{(\mathrm{P} 1)}=\Delta \phi_{\mathrm{eq}, \mathrm{av}}^{(\mathrm{P} 2)}$ and $\Delta \phi_{\mathrm{eq}}^{(\mathrm{P} 3)} \geq \Delta \phi_{\mathrm{eq}, \mathrm{av}}^{(\mathrm{P} 4)}$, we see that the $\Delta \phi_{\mathrm{eq}}$ value obtained from the distribution process of $\mathrm{A}^{-} \rightleftharpoons \mathrm{A}_{\mathrm{o}}^{-}$is essentially equivalent to that from the combined process of $\mathrm{M}^{+} \rightleftharpoons \mathrm{M}_{\mathrm{o}}^{+}$and $\mathrm{ML}^{+} \rightleftharpoons \mathrm{ML}_{\mathrm{o}}^{+} \quad$ [8] \{see Equations (1) \& (2)\} or $\mathrm{M}^{2+} \rightleftharpoons \mathrm{M}_{\mathrm{o}}^{2+}, \mathrm{MLA}^{+} \rightleftharpoons \mathrm{MLA}_{\mathrm{o}}^{+}$and $\mathrm{ML}^{2+} \rightleftharpoons \mathrm{ML}_{\mathrm{o}}^{2+} \quad$ see Equations (7) \& (8) $\}$ into $\mathrm{o}=\mathrm{DCE}$ and NB.

\subsection{Experimental Proof of $K_{\mathrm{ex} \pm}$ and $K_{\mathrm{ex} 2 \pm}$ without $\Delta \phi_{\mathrm{eq}}$}

We obtained the $\log K_{\text {ext }}$ values of the AgPic extraction with B18C6 into DCE from the relation (a) in Table 1 with $\log K_{\mathrm{D}, \mathrm{Ag}}^{\mathrm{S}}=-4.502$ [9] $\left(=-\Delta \phi_{\mathrm{Ag}}^{0 \prime} / 0.05916\right.$ [3]), $\log K_{\mathrm{D}, \text { Pic }}^{\mathrm{S}}=-1.01_{1}$ [11] (into DCE) and the corres ponding $\log K_{\mathrm{ML}, \mathrm{DCE}}$ value in Table 2(a). These values, expressed as $\log K_{\mathrm{ex} \pm}^{(\mathrm{K} 5)}$ below, are in good agreement with those listed in Table 2(a).

The $K_{\mathrm{D}, \mathrm{AgL}}$ calculation can be an indirect proof of $K_{\mathrm{ex} \pm}$ without $\Delta \phi_{\mathrm{eq}}$. First, the log $K_{\mathrm{D}, \mathrm{AgL}}$ values (namely $\log K_{\mathrm{D}, \mathrm{AgL}}^{\mathrm{S}}$ ones) standardized at $\Delta \phi_{\mathrm{eq}}=0 \mathrm{~V}$ for $\mathrm{L}=$ B18C6 were calculated from the modified form, $\log K_{\mathrm{D}, \mathrm{AgL}}^{\mathrm{S}}=\log K_{\mathrm{ex} \pm}-\log K_{\mathrm{D}, \mathrm{Pic}}^{\mathrm{S}}-\log K_{\mathrm{AgL}}+\log K_{\mathrm{D}, \mathrm{L}}$, of the relation (b) in Table 1. The obtained values are 
shown as $K_{\mathrm{D}, \mathrm{AgL}}^{\mathrm{S}(\mathrm{KG})}$ in Table 2(d). In this calculation, we employed $\log K_{\mathrm{D}, \text { Pic }}^{\mathrm{S}}=-1.01_{1}$ [11] (into DCE), $\log K_{\mathrm{AgL}}\left\{=\log \left(\left[\mathrm{AgL}^{+}\right] /\left[\mathrm{Ag}^{+}\right][\mathrm{L}]\right)\right\}=1.83$ [15] (in water), $\log K_{\mathrm{D}, \mathrm{B18C6} 6}\left\{=\log \left([\mathrm{B} 18 \mathrm{C} 6]_{\mathrm{DCE}} /[\mathrm{B} 18 \mathrm{C} 6]\right)\right\}=2.009$ [16] at $298 \mathrm{~K}$.

Next, the $\log K_{\mathrm{D}, \mathrm{AgL}}$ values were reproduced by using the equation, $\log K_{\mathrm{D}, \mathrm{AgL}}\left\{=\log \left(\left[\mathrm{AgL}^{+}\right]_{0} /\left[\mathrm{AgL}^{+}\right]\right)\right\}=\Delta \phi_{\mathrm{eq}} / 0.05916+\log K_{\mathrm{D}, \mathrm{AgL}}^{\mathrm{S}}$ at $298 \mathrm{~K}$ (see Appendix in ref. [3] for its detailed derivation), with the calculated $\log K_{\mathrm{D}, \mathrm{AgL}}^{\mathrm{S}(\mathrm{K} 6)}$ values and the $\Delta \phi_{\mathrm{eq}, \mathrm{av}}^{(\mathrm{P} 2)}$ ones. These $\log K_{\mathrm{D}, \mathrm{AgL}}^{(\mathrm{K} 7)}$ values in Table 2(d) are in good accordance with the values listed in Table 2(a). Thus the $\log K_{\mathrm{D}, \mathrm{AgL}}$ values can be well reproduced. From the results of $K_{\mathrm{ex} \pm}^{(\mathrm{K} 5)} \& K_{\mathrm{D}, \mathrm{AgL}}^{(\mathrm{K} 7)}$ at least, we can see that Equation (11) is valid for the Ag Pic-B18C6 extraction system.

Moreover, an average $\log K_{\mathrm{D}, \mathrm{AgL}}^{\mathrm{S}}$ value for all the $\log K_{\mathrm{D}, \mathrm{AgL}}^{\mathrm{S}(\mathrm{KG})}$ ones was $1.3_{9} \pm 0.2_{3}$. From this value and the $\Delta \phi_{\mathrm{eq}}^{(\mathrm{P1})}$ ones, we calculated the $\log K_{\mathrm{D}, \mathrm{AgL}}$ values again, using the above relation [3]. The value obtained from $\Delta \phi_{\mathrm{eq}}^{(\mathrm{P} 1)}$ of no. 1C was under-estimated by $|0.3|$ and that of no. 2 was over-estimated by the same, compared to those in Table 2(a) or of $\log K_{\mathrm{D}, \mathrm{AgL}}^{(\mathrm{K} 7)}$. On the other hand, the $\log K_{\mathrm{D}, \mathrm{AgL}}$ values (= $3.1 \& 2.7$, respectively) of nos. $1 \mathrm{~A}$ and $1 \mathrm{~B}$ were close to those in Table 2(a).

The $\log K_{\text {ex }}$ values for the M(II)-B18C6 extraction into NB were calculated from the relation (c) in Table 1.

These $\log K_{\mathrm{ex} \pm}^{(\mathrm{K} 8)}$ values are in accordance with the values in Table 3(a); the $\log K_{\mathrm{ex} \pm}$ values in Table 3(a) have been determined by the procedure [2] [7] described in Appendix II. This accordance indicates that Equation (11) without $\Delta \phi_{\mathrm{eq}}$ is satisfied. In this calculation, $\log K_{\mathrm{D}, \mathrm{Ca}}^{\mathrm{S}}=-11.80, \log K_{\mathrm{D}, \mathrm{Sr}}^{\mathrm{S}}=-11.56, \log K_{\mathrm{D}, \mathrm{Ba}}^{\mathrm{S}}=-10.82$ [10], $\log K_{\mathrm{CaL}, \mathrm{NB}}=11.2, \log K_{\mathrm{SrL}, \mathrm{NB}}=13.1, \log K_{\mathrm{BaL}, \mathrm{NB}}=13.4$ for $\mathrm{L}=18 \mathrm{C} 6[17], \log K_{\mathrm{CaL}, \mathrm{NB}}=9.43, \log K_{\mathrm{SrL}, \mathrm{NB}}=$ 11.1 and $\log K_{\mathrm{BaL}, \mathrm{NB}}=11.6$ for $\mathrm{L}=\mathrm{B} 18 \mathrm{C} 6$ [17] were employed. Also, the $\log K_{\mathrm{D}, \mathrm{M}}$ values were calculated from the modified form of Equation (3), $\log K_{\mathrm{D}, \mathrm{M}}=2 \Delta \phi_{\mathrm{eq}} / 0.05916+\log K_{\mathrm{D}, \mathrm{M}}^{\mathrm{S}}$, with the $\Delta \phi_{\mathrm{eq}}^{(\mathrm{P} 3)}$ values, where the $\log K_{\mathrm{D}, \mathrm{Pic}}\left\{=\Delta \phi_{\mathrm{eq}}^{(\mathrm{P} 3)} / 0.05916+0.05\right\}$ values in Table 3(a) corresponding to them were employed accordingly.

The following discussion is similar to that from $K_{\mathrm{D}, \mathrm{AgL}}^{\mathrm{S}}$ to $K_{\mathrm{D}, \mathrm{AgL}}$ at $\mathrm{L}=\mathrm{B} 18 \mathrm{C} 6$ (Table 2(d)). The $\log K_{\mathrm{D}, \mathrm{ML}}^{\mathrm{S}}$ values at $\mathrm{M}(\mathrm{II})$ were calculated from a modified form, $\log K_{\mathrm{D}, \mathrm{ML}}^{\mathrm{S}}=\log K_{\mathrm{ex} 2 \pm}-2 \log K_{\mathrm{D}, \mathrm{A}}^{\mathrm{S}}-\log K_{\mathrm{ML}}+\log K_{\mathrm{D}, \mathrm{L}}$, of the relation (f) in Table 1. Here, the adopted $\log K_{\mathrm{ML}}\left\{=\log \left(\left[\mathrm{ML}^{2+}\right] /\left[\mathrm{M}^{2+}\right][\mathrm{L}]\right)\right\}$, in water at $\left.298 \mathrm{~K}\right\}$ values were 0.48 for the Ca-18C6 [18] and -B18C6 [19] systems, 2.72 [20] for Sr-18C6, 3.87 [20] for Ba-18C6, 2.41 [15] for Sr-B18C6 and 2.90 [13] for Ba-B18C6. Also, $\log K_{\mathrm{D}, \mathrm{Pic}}^{\mathrm{S}}=0.05$ [11] (into NB), $\log K_{\mathrm{D}, 18 \mathrm{C} 6}=-1.00$ [21] and $\log K_{\mathrm{D}, \mathrm{B} 18 \mathrm{C} 6}=1.57$ [17] (into NB) at $298 \mathrm{~K}$ were used for calculation. Furthermore, from the assumption in the section 2.2, we employed the $\log K_{\text {ex2 }}$ values [12] which have been reported before and their values virtually correspond to the ones standardized at $\Delta \phi_{\text {eq }}=0 \mathrm{~V}$ (see Table 3(a)).

The calculated $\log K_{\mathrm{D}, \mathrm{ML}}^{\mathrm{S}(\mathrm{M})}$ values are listed in Table 3(d). These values agreed well with those [17] previously-reported by the ion-transfer polarographic measurements, except for the Ba-18C6 and -B18C6 systems. This fact indirectly indicates that Equation (12) is satisfied. For the Ba-18C6 and -B18C6 systems, -2.6 for the former and -0.8 for the latter have been reported [17].

As similar to $\log K_{\mathrm{D}, \mathrm{AgL}}^{(\mathrm{K})}$ in Table 2(d), the calculation of $\log K_{\mathrm{D}, \mathrm{ML}}$ becomes the indirect proof of $\log K_{\mathrm{ex} 2 \pm}$ without $\Delta \phi_{\mathrm{eq}}$. Then, the $\log K_{\mathrm{D}, \mathrm{ML}}$ values at $298 \mathrm{~K}$ were estimated from the $\log K_{\mathrm{D}, \mathrm{ML}}^{\mathrm{S}(\mathrm{K} 9)}$ ones and the equation, $\log K_{\mathrm{D}, \mathrm{ML}}\left\{=2 f\left(\Delta \phi_{\mathrm{eq}}-\Delta \phi_{\mathrm{ML}}^{0}\right) / 2.303\right\}=2 \Delta \phi_{\mathrm{eq}} / 0.05916+\log K_{\mathrm{D}, \mathrm{ML}}^{\mathrm{S}} \quad$ [7]; the $\Delta \phi_{\mathrm{eq}}^{(\mathrm{P} 3)}$ values were used here.

The thus-calculated $\log K_{\mathrm{D}, \mathrm{ML}}^{(\mathrm{K} 10)}$ values were close to the values listed in Table 3(a); the experimental $\log K_{\mathrm{D}, \mathrm{ML}}$ values in Table 3(a) have been calculated from the relation (d) in Table 1 [7]. This fact indicates that Equation (12) satisfies indirectly the thermodynamic cycle of (f). 
Table 3. (a) Fundamental data for the extraction of $\mathrm{MPic}_{2}\left(\mathrm{M}=\mathrm{Ca}\right.$, Sr\& Ba) by L into NB at $298 \mathrm{~K}$. ; (b) Evaluated $\Delta \phi_{\mathrm{eq}}$ values; (c) Reproduced $\log K_{\mathrm{ex} \pm}$ values; (d) Evaluated $\log K_{\mathrm{D}, \mathrm{ML}}^{\mathrm{s}}$ and reproduced $\log K_{\mathrm{D}, \mathrm{ML}}$ values.

(a)

\begin{tabular}{|c|c|c|c|c|c|c|}
\hline $\mathrm{L}$ & M & $\log K_{\mathrm{ex} \pm}$ & $\log K_{\mathrm{D}, \mathrm{A}}$ & $\log K_{1, \mathrm{NB}}\left(I_{\mathrm{NB}}^{\mathrm{b}} / 10^{-4}\right)$ & $\log K_{\mathrm{D}, \mathrm{ML}}$ & $\log K_{\text {ex2 }}{ }^{\mathrm{c}}$ \\
\hline \multirow[t]{3}{*}{$18 \mathrm{C} 6$} & $\mathrm{Ca}$ & 5.44 & -1.43 & $5.9(8.9)$ & $0.8_{8}$ & -0.5 \\
\hline & $\mathrm{Sr}$ & $6.9_{2}$ & -0.98 & $5.3(4.8)$ & $-0.1_{7}$ & 1.6 \\
\hline & $\mathrm{Ba}$ & $7.3_{5}$ & -0.69 & 4.9 (5.9) & $-0.9_{9}$ & $2.7^{\mathrm{d}}$ \\
\hline \multirow[t]{3}{*}{ B18C6 } & $\mathrm{Ca}$ & $2.7_{1}$ & -1.92 & $5.0(6.9)$ & $2.6_{2}$ & -2.3 \\
\hline & $\mathrm{Sr}$ & 4.34 & -1.34 & $4.7(2.3)$ & $1.4_{4}$ & -0.4 \\
\hline & $\mathrm{Ba}$ & $5.0_{1}$ & -1.17 & $4.1(2.1)$ & $1.6_{1}$ & $0.9^{\mathrm{d}}$ \\
\hline
\end{tabular}

${ }^{\mathrm{a}}$ Ref. [7]; ${ }^{\mathrm{b} U n i t: ~} \mathrm{~mol} \mathrm{dm}{ }^{-3} ;{ }^{\mathrm{c}} \log K_{\text {exz }}^{\mathrm{s}}$ values: see ref [12]; ${ }^{\mathrm{d}}$ Values re-calculated from the data in ref [12].

(b)

\begin{tabular}{cccccccc}
\hline & \multicolumn{3}{c}{ 18C6 extraction system } & \multicolumn{3}{c}{ B18C6 extraction system } \\
\cline { 2 - 7 } & $\mathrm{M}=\mathrm{Ca}$ & $\mathrm{Sr}$ & $\mathrm{Ba}$ & $\mathrm{M}=\mathrm{Ca}$ & $\mathrm{Sr}$ & $\mathrm{Ba}$ \\
\hline$\Delta \phi_{\mathrm{eq}}^{(\mathrm{P} 3)} / \mathrm{V}$ & 0.088 & 0.061 & 0.044 & 0.12 & 0.082 & 0.072 \\
$\Delta \phi_{\mathrm{eq}, \mathrm{av}}^{(\mathrm{P})} / \mathrm{V}$ & $0.080 \pm 0.008$ & $0.051 \pm 0.008$ & $0.036 \pm 0.006$ & $0.097 \pm 0.008$ & $0.059 \pm 0.008$ & $0.04_{2} \pm 0.01_{0}$ \\
\hline
\end{tabular}

(c)

\begin{tabular}{ccccccc}
\hline & \multicolumn{3}{c}{ 18C6 extraction system } & \multicolumn{3}{c}{ B18C6 extraction system } \\
\cline { 2 - 7 } & $\mathrm{M}=\mathrm{Ca}$ & $\mathrm{Sr}$ & $\mathrm{Ba}$ & $\mathrm{M}=\mathrm{Ca}$ & $\mathrm{Sr}$ & $\mathrm{Ba}$ \\
\hline $\log K_{\mathrm{ex} \pm}^{(\mathrm{K} 8)} *$ & 5.4 & 7.0 & 7.6 & 2.7 & 4.4 & 5.3 \\
\hline
\end{tabular}

${ }^{*} \log K_{\mathrm{ext}}^{(\mathrm{K} 8)}=\left\{2 \Delta \phi_{\mathrm{eq}}^{(\mathrm{PP})} / 0.05916+\log K_{\mathrm{D}, \mathrm{M}}^{\mathrm{s}}[10]\right\}+2 \log K_{\mathrm{D}, \mathrm{A}}^{(\text {Tables(a)) }}-\log K_{\mathrm{ML}, \text { org }}[17]+\log K_{\mathrm{d}, \mathrm{org}}^{\text {(Tables(a)) }}$.

(d)

\begin{tabular}{cccccccc}
\hline & $\mathrm{L}=18 \mathrm{C} 6$ & & \multicolumn{2}{c}{$\mathrm{B} 18 \mathrm{C} 6$} \\
\cline { 2 - 7 } & $\mathrm{M}=\mathrm{Ca}$ & $\mathrm{Sr}$ & $\mathrm{Ba}$ & $\mathrm{M}=\mathrm{Ca}$ & $\mathrm{Sr}$ & $\mathrm{Ba}$ \\
\hline $\log K_{\mathrm{D}, \mathrm{ML}}^{\mathrm{S(K9)*}}$ & -2.1 & -2.2 & -2.3 & -1.3 & -1.3 & -0.5 \\
$\log K_{\mathrm{D}, \mathrm{ML}}^{(\mathrm{K} 10)}$ & 0.9 & -0.1 & -0.8 & 2.7 & 1.5 & 1.9 \\
\hline
\end{tabular}

${ }^{*} \log K_{\mathrm{D}, \mathrm{ML}}^{\mathrm{s(K9)}}=\log K_{\mathrm{exz} \pm}^{\mathrm{s}}[12]-2 \log K_{\mathrm{D}, \mathrm{A}}^{\mathrm{s}}-\log K_{\mathrm{ML}}[13][15] \&[18]-[20]+\log K_{\mathrm{D}, \mathrm{L}}[17][21] .{ }^{\S} \log K_{\mathrm{D}, \mathrm{ML}}^{(\mathrm{K} 10)}=2 \Delta \phi_{\mathrm{eq}}^{(\mathrm{P3})} / 0.05916+\log K_{\mathrm{D}, \mathrm{ML}}^{\mathrm{s}(\mathrm{K} 9)}$.

The above calculation results for the AgPic and $\mathrm{MPic}_{2}$ extraction with $\mathrm{L}$ indicate that the assumption of Equations (11) and (12) without $\Delta \phi_{\mathrm{eq}}$ is essentially valid. In other words, the overall extraction constants, $K_{\mathrm{ex} \pm}$ and $K_{\text {ex2 }}$, must be expressed rationally as functions without $\Delta \phi_{\mathrm{eq}}$.

\subsection{For Applications to Other Extraction Systems}

The above handling based on Table 1 can be also applied to the practical extraction equilibria of

$$
\begin{gathered}
\mathrm{M}^{+}+\mathrm{A}^{-} \rightleftharpoons \mathrm{M}_{\mathrm{o}}^{+}+\mathrm{A}_{\mathrm{o}}^{-} \text {into o }=\mathrm{NB} \text { [14], } \\
\mathrm{R}_{4} \mathrm{~N}^{+}+\mathrm{A}^{-} \rightleftharpoons \mathrm{R}_{4} \mathrm{NA}_{\mathrm{o}} \text { into DCE [22] and } \mathrm{CH}_{2} \mathrm{Cl}_{2}[23], \\
\mathrm{T}^{-}+\mathrm{A}_{\mathrm{IL}}^{-} \rightleftharpoons \mathrm{T}_{\mathrm{IL}}^{-}+\mathrm{A}^{-} \text {into } \mathrm{IL}=\text { an ionic liquid phase [24] [25], }
\end{gathered}
$$




$$
\begin{aligned}
\mathrm{H}^{+}+\mathrm{L}_{\mathrm{o}}+\mathrm{AuCl}_{4}^{-} & \rightleftharpoons \mathrm{HLAuCl}_{4, \mathrm{o}} \text { into DCE [26], } \\
\mathrm{Pb}^{2+}+\mathrm{L}_{\mathrm{o}}+2 \mathrm{SCN}^{-} & \rightleftharpoons \mathrm{PbL}(\mathrm{SCN})_{2, \mathrm{o}} \quad \text { into NB [27] }
\end{aligned}
$$

and

$$
\mathrm{Pu}^{4+}+\mathrm{L}_{\mathrm{o}}+2 \mathrm{H}^{+}+6 \mathrm{Cl}^{-} \rightleftharpoons \mathrm{HL}\left[\mathrm{HPuCl}_{6}\right]_{\mathrm{o}} \text { into NB [28]. }
$$

As examples, thermodynamic points of view suggest the following cycles for the above equilibria:

$$
\begin{gathered}
K_{\mathrm{ex}}=K_{\mathrm{D}, \mathrm{M}} K_{\mathrm{D}, \mathrm{A}}, \\
K_{\mathrm{ex}}=K_{\mathrm{D}, \mathrm{C}} K_{\mathrm{D}, \mathrm{A}} K_{\mathrm{CA}, \mathrm{DCE}} \text { at } \mathrm{C}^{+}=\mathrm{R}_{4} \mathrm{~N}^{+}, \\
K_{\mathrm{ex}, \mathrm{IE}}=K_{\mathrm{D}, \mathrm{T}} / K_{\mathrm{D}, \mathrm{A}}, \\
K_{\mathrm{ex}}=K_{\mathrm{D}, \mathrm{H}} K_{\mathrm{D}, \mathrm{AuCl} 4} K_{\mathrm{HL}, \mathrm{DCE}} K_{1, \mathrm{DCE}}
\end{gathered}
$$

with $K_{\mathrm{HL}, \mathrm{DCE}}=\left[\mathrm{HL}^{+}\right]_{\mathrm{DCE}} /\left(\left[\mathrm{H}^{+}\right]_{\mathrm{DCE}}[\mathrm{L}]_{\mathrm{DCE}}\right)$ and $K_{1, \mathrm{DCE}}=\left[\mathrm{HLAuCl}_{4}\right]_{\mathrm{DCE}} /\left(\left[\mathrm{HL}^{+}\right]_{\mathrm{DCE}}\left[\mathrm{AuCl}_{4}^{-}\right]_{\mathrm{DCE}}\right)$,

$$
K_{\mathrm{ex}}=K_{\mathrm{D}, \mathrm{Pb}}\left(K_{\mathrm{D}, \mathrm{SCN}}\right)^{2} K_{\mathrm{PbL}, \mathrm{NB}} K_{1, \mathrm{NB}} K_{2, \mathrm{NB}}
$$

and

$$
K_{\mathrm{ex}}=\left(K_{\mathrm{D}, \mathrm{H}}\right)^{2} K_{\mathrm{D}, \mathrm{Pu}}\left(K_{\mathrm{D}, \mathrm{Cl}}\right)^{6} K_{\mathrm{HL}, \mathrm{NB}} \beta_{6, \mathrm{NB}} K_{\mathrm{HPuCl} 6, \mathrm{NB}} K_{1, \mathrm{NB}}
$$

with $\beta_{6, \mathrm{NB}}=\left[\mathrm{PuCl}_{6}^{2-}\right]_{\mathrm{NB}} /\left\{\left[\mathrm{Pu}^{4+}\right]_{\mathrm{NB}}\left(\left[\mathrm{Cl}^{-}\right]_{\mathrm{NB}}\right)^{6}\right\}, \quad K_{\mathrm{HPuCl}, \mathrm{NB}}=\left[\mathrm{HPuCl}_{6}^{-}\right]_{\mathrm{NB}} /\left(\left[\mathrm{H}^{+}\right]_{\mathrm{NB}}\left[\mathrm{PuCl}_{6}^{2-}\right]_{\mathrm{NB}}\right) \quad$ and $K_{1, \mathrm{NB}}=\left[\mathrm{HL}^{+} \mathrm{HPuCl}_{6}^{-}\right]_{\mathrm{NB}} /\left(\left[\mathrm{HL}^{+}\right]_{\mathrm{NB}}\left[\mathrm{HPuCl}_{6}^{-}\right]_{\mathrm{NB}}\right)$, respectively. Similarly, only the $K_{\mathrm{D}, j}$ values are expressed as functions with the $\Delta \phi_{\text {eq }}$ ones.

The relation, $\log K_{\mathrm{ex}}=\log K_{\mathrm{D}, \mathrm{M}}+\log K_{\mathrm{D}, \mathrm{A}}$, for the process (E11) can be arranged into $\log K_{\mathrm{D}, \mathrm{M}}+\log K_{\mathrm{D}, \mathrm{A}}\left\{=f\left(\Delta \phi_{\mathrm{eq}}-\Delta \phi_{\mathrm{M}}^{0 \prime}\right) / 2.303-f\left(\Delta \phi_{\mathrm{eq}}-\Delta \phi_{\mathrm{A}}^{0^{\prime}}\right) / 2.303\right\}=\log K_{\mathrm{D}, \mathrm{M}}^{\mathrm{S}}+\log K_{\mathrm{D}, \mathrm{A}}^{\mathrm{S}}$. This does not contradict the fact [14] that the determination of $K_{\mathrm{ex}}\left(=\left[\mathrm{M}^{+}\right]_{\mathrm{NB}}\left[\mathrm{A}^{-}\right]_{\mathrm{NB}} /\left[\mathrm{M}^{+}\right]\left[\mathrm{A}^{-}\right]\right)$by solvent extraction experiments gives $K_{\mathrm{D}, \mathrm{M}}^{\mathrm{S}}$ and $K_{\mathrm{D}, \mathrm{A}}^{\mathrm{S}}$, when either $K_{\mathrm{D}, \mathrm{M}}$ or $K_{\mathrm{D}, \mathrm{A}}$ was standardized at $\Delta \phi_{\mathrm{eq}}=0 \mathrm{~V}$ which is based on the $\mathrm{Ph}_{4} \mathrm{As}^{+} \mathrm{BPh}_{4}{ }^{-}$assumption [14] [29] \& [30]. Also, $K_{\mathrm{D}, \mathrm{C}}$ cancels out $K_{\mathrm{D}, \mathrm{A}}$ in (E12c): $\log K_{\mathrm{D}, \mathrm{C}}+\log K_{\mathrm{D}, \mathrm{A}}\left\{=f\left(\Delta \phi_{\mathrm{eq}}-\Delta \phi_{\mathrm{C}}^{0^{\prime}}\right) / 2.303-f\left(\Delta \phi_{\mathrm{eq}}-\Delta \phi_{\mathrm{A}}^{0^{\prime}}\right) / 2.303\right\}=\log K_{\mathrm{D}, \mathrm{C}}^{\mathrm{S}}+\log K_{\mathrm{D}, \mathrm{A}}^{\mathrm{S}}$. For $\mathrm{C}^{+}=\left(\mathrm{C}_{4} \mathrm{H}_{9}\right)_{4} \mathrm{~N}^{+}$ and $\mathrm{A}^{-}=$Pic $^{-}$, the $\left(\log K_{\mathrm{D}, \mathrm{C}}^{\mathrm{S}}+\log K_{\mathrm{D}, \mathrm{A}}^{\mathrm{S}}\right)$ value becomes $2.66\left(=\log K_{\mathrm{ex}}-\log K_{\mathrm{CA}, \mathrm{DCE}}\right.$ [22]) and accordingly we have obtained the $\log K_{\mathrm{D}, \mathrm{C}}^{\mathrm{S}}$ value at $298 \mathrm{~K}$ from the experimental $\log K_{\mathrm{D}, \mathrm{A}}^{\mathrm{S}}$ one [11].

Similarly, $K_{\mathrm{D}, \mathrm{T}}$ cancels out $K_{\mathrm{D}, \mathrm{A}}$ in (E13c), where $\mathrm{T}^{-}$denotes another anion. That is, $\log K_{\mathrm{D}, \mathrm{T}}-\log K_{\mathrm{D}, \mathrm{A}}\left\{=-f\left(\Delta \phi_{\mathrm{eq}}-\Delta \phi_{\mathrm{T}}^{0^{\prime}}\right) / 2.303+f\left(\Delta \phi_{\mathrm{eq}}-\Delta \phi_{\mathrm{A}}^{0^{\prime}}\right) / 2.303\right\}=\log K_{\mathrm{D}, \mathrm{T}}^{\mathrm{S}}-\log K_{\mathrm{D}, \mathrm{A}}^{\mathrm{S}}$. For the overall equilibria, (E14) \& (E15), one can handle them in the same manner as that described above for the AgPic and $\mathrm{MPic}_{2}$ extraction with L, respectively.

We can easily see that the $K_{\mathrm{D}, \mathrm{H}}$ and $K_{\mathrm{D}, \mathrm{Pu}}$ values cancel out the $K_{\mathrm{D}, \mathrm{Cl}}$ one in (E16c). That is, $2 \log K_{\mathrm{D}, \mathrm{H}}+\log K_{\mathrm{D}, \mathrm{Pu}}+6 \log K_{\mathrm{D}, \mathrm{Cl}}$ equals

$2 \cdot f\left(\Delta \phi_{\mathrm{eq}}-\Delta \phi_{\mathrm{H}}^{0^{\prime}}\right) / 2.303+4 f\left(\Delta \phi_{\mathrm{eq}}-\Delta \phi_{\mathrm{Pu}}^{0 \prime}\right) / 2.303-6 \cdot f\left(\Delta \phi_{\mathrm{eq}}-\Delta \phi_{\mathrm{Cl}}^{0 \prime}\right) / 2.303$ and then becomes $2 \log K_{\mathrm{D}, \mathrm{H}}^{\mathrm{S}}+\log K_{\mathrm{D}, \mathrm{Pu}}^{\mathrm{S}}+6 \log K_{\mathrm{D}, \mathrm{Cl}}^{\mathrm{S}}$. We found the $\Delta \phi_{\mathrm{PuO}_{2}}^{0}{ }^{\prime}$ value $\left\{=-(0.05916 / 2) \log \left(\left[\mathrm{PuO}_{2}^{2+}\right]_{\mathrm{NB}} /\left[\mathrm{PuO}_{2}^{2+}\right]\right)\right.$ 
$=0.035 \mathrm{~V}[29]$ at $298 \mathrm{~K}$ \}, but were not able to find the $\Delta \phi_{\mathrm{Pu}}^{0 \prime}$ value in references.

\section{Conclusion}

It was demonstrated that the $\Delta \phi_{\mathrm{eq}}$ values calculated from the experimental $\log K_{\mathrm{D} \text {,Pic }}$ ones are in agreement with or close to those more-accurately done from the charge balance equations for the species with M(I) in the DCE phase and with $\mathrm{M}(\mathrm{II})$ in the NB one, except for some cases. This demonstration indicates that the plots of $\log K_{\mathrm{ex}}^{\mathrm{mix}}$ versus $-\log \left(\left[\mathrm{M}^{+}\right][\mathrm{L}]_{0}\left[\mathrm{~A}^{-}\right]^{\mathrm{z}-1}\right)$, described in Appendix II with $z=1 \quad \& 2$, yield the practical $K_{\mathrm{D}, \mathrm{A}}$ values and then the first-approximated $\Delta \phi_{\mathrm{eq}}$ ones. These results will give an answer to how one explain the differences in $K_{\mathrm{D}, \mathrm{A}}$ among extraction experiments of various $\mathrm{MA}$ or $\mathrm{MA}_{2}$ by various L. Also, we clarified that the assumption of Equations (11) and (12) is valid for the AgPic and MPic 2 extraction with 18C6 and/or B18C6. This eliminated the contradictions [3] [7] due to $\Delta \phi_{\mathrm{eq}}$ from the thermodynamic cycles. Moreover, the present work indicates a possibility that the proposed handling can be applied to various extraction systems with neutral ligands at least.

\section{Acknowledgements}

The authors thank Mr. Tomohiro Amano, Mr. Satoshi Ikeda and Mr. Yuki Ohsawa for their experimental assistances.

\section{References}

[1] Kudo, Y., Harashima, K., Katsuta, S. and Takeda, Y. (2011) Solvent Extraction of Sodium Permanganate by Monobenzo-3m-Crown- $m$ Ethers $(m=5,6)$ into 1,2-Dichloroethane and Nitrobenzene: A Method which Analyzes the Extraction System with the Polar Diluents. International Journal of Chemistry, 3, 99-107. http://dx.doi.org/10.5539/ijc.v3n1p99

[2] Kudo, Y., Takahashi, Y., Numako, C. and Katsuta, S. (2014) Extraction of Lead Picrate by 18-crown-6 Ether into Various Diluents: Examples of Sub-Analysis of Overall Extraction Equilibrium Based on Component Equilibria. Journal of Molecular Liquids, 194, 121-129. http://dx.doi.org/10.1016/j.molliq.2014.01.017

[3] Kudo, Y., Ogihara, M., Katsuta, S. and Takeda, Y. (2014) An Electrochemical Understanding of Extraction of Silver Picrate by Benzo-3m-Crown- $m$ Ethers $(m=5,6)$ into 1,2-Dichloroethane and Dichloromethane. American Journal of Analytical Chemistry, 5, 433-444. http://dx.doi.org/10.4236/ajac.2014.57052

[4] Valente, M., Sousa, S.F., Magalhães, A.L. and Freire, C. (2010) Crown-Ether Type Podands as Alkali Metal Cation Extractants: Interface of the Number of Oxygens in the Chain. Journal of Solution Chemistry, 39, 1230-1242. http://dx.doi.org/10.1007/s10953-010-9579-9

[5] Valente, M., Sousa, S.F., Magalhães, A.L. and Freire, C. (2011) Complexation of Alkali Metal Cations by CrownEther Type Podands with Applications in Solvent Extraction: Insights from Quantum Chemical Calculations. Journal of Molecular Model, 17, 3275-3288. http://dx.doi.org/10.1007/s00894-011-1004-9

[6] Kudo, Y., Horiuchi, N., Katsuta, S. and Takeda, Y. (2013) Extraction of Cadmium Bromide and Picrate by 18-crown-6 Ether into Various Less-Polar Diluents: Analysis of Overall Extraction Equilibria Based on Their Component Equilibria with Formation of Their Ion Pairs in Water. Journal of Molecular Liquids, 177, 257-266. http://dx.doi.org/10.1016/j.molliq.2012.10.015

[7] Kudo, Y. and Takeuchi, T. (2014) On the Interfacial Potential Differences for the Extraction of Alkaline-Earth Metal Picrates by 18-Crown-6 Ether Derivatives into Nitrobenzene. Journal of Thermodynamics \& Catalysis, 5, 6 pp. http://dx.doi.org/10.4172/2157-7544.1000133

[8] Takeda, Y., Ezaki, T., Kudo, Y. and Matsuda, H. (1995) Distribution Study on Electroneutral ans Protonated Amino Acids between Water and Nitrobenzene. Determination of the Standard Ion-Transfer Potentials of Protonated Amino Acids. Bulletin of the Chemical Society of Japan, 68, 787-790. http://dx.doi.org/10.1246//bcsj.68.787

[9] Marcus, Y. (1983) Thermodynamic Functions of Transfer of Single Ions from Water to Nonaqueous and Mixed Solvents: Part 1-Gibbs Free Energies of Transfer to Nonaqueous Solvents. Pure \& Applied Chemistry, 55, 977-1021.

[10] Pivoňková, M. and Kyrš, M. (1969) The Distribution of Alkaline Earth Dipicrylaminates and Tetraphenylborates Between Water and Nitrobenzene Phases. Journal of Inorganic and Nuclear Chemistry, 31, 175-185. http://dx.doi.org/10.1016/0022-1902(69)80066-7

[11] Kudo, Y., Harashima, K., Hiyoshi, K., Takagi, J., Katsuta, S. and Takeda, Y. (2011) Extraction of Some Univalent 
Salts into 1,2-Dichloroethane and Nitrobenzene: Analysis of Overall Extraction Equilibrium Based on Elucidating Ion-Pair Formation and Evaluation of Standard Potentials for Ion Transfers at the Interfaces between Their Diluents and Water. Analytical Sciences, 27, 913-919. http://dx.doi.org/10.2116/analsci.27.913

[12] Kudo, Y., Katsuta, S. and Takeda, Y. (2012) Evaluation of Overall Extraction Constants for the Crown Ether-Complex Ions of Alkali and Alkaline-Earth Metal with Counter Picrate Ions from Water into Nitrobenzene Based on Their Component Equilibrium Constants. Journal of Molecular Liquids, 173, 66-70. http://dx.doi.org/10.1016/j.molliq.2012.06.003

[13] Umegaki, T. (1983) Su-gakuYo-koKo-shiki-syu (Handbook of Mathematical Formula, 4th Edition). Komatsu, Y., Ed., Hirokawa Publishing Co., Tokyo, Chap. 3, 78-79. (In Japanese)

[14] Rais, J. (1976) Individual Extraction Constants of Univalent Ions in the System Water-Nitrobenzene. Collection of Czechoslovak Chemical Communications, 36, 3253-3262. http://dx.doi.org/10.1135/cccc19713253

[15] Takeda, Y., Kohno, R., Kudo, Y. and Fukada, N. (1989) Stabilities in Water and Transfer Activity Coefficients from Water to Nonaqueous Solvents of Benzo-18-crown-6-Metal Ion Complexes. Bulletin of the Chemical Society of Japan, 62, 999-1003. http://dx.doi.org/10.1246/bcsj.62.999

[16] Takeda, Y. (2002) Extraction of Alkali Metal Picrates with 18-crown-6, benzo-18-crown-6, and Dibenzo-18-crown-6 into Various Organic Solvents. Elucidation of Fundamental Equilibria Governing Extraction-Ability and -Selectivity. Bunseki Kagaku (Analytical Chemistry), 51, 515-525. (In Japanese)

[17] Kudo, Y., Miyakawa, T., Takeda, Y., Matsuda, H. and Yajima, S. (1996) Ion-Transfer Polarographic Study of the Distribution of Alkali and Alkaline-Earth Metal Complexes with 3m-crown-m Ether Derivatives $(m=6,8)$ between Water and Nitrobenzne Phases. Journal of Inclusion Phenomena and Molecular Recognition in Chemistry, 26, 331-341. http://dx.doi.org/10.1007/BF01053550

[18] Høiland, H., Ringseth, J.A. and Brun, T.S. (1979) Cation-Crown Ether Complex Formation in Water. II. Alkali and Alkaline Earth Cations and 12-crown-4, 15-crown-5, and 18-crown-6. Journal of Solution Chemistry, 8, 779-792. http://dx.doi.org/10.1007/BF00648577

[19] Takeda, Y. and Nishida, M. (1989) Solvent Extraction of Various Metal Picrates with Benzo-18-crown-6 into $\mathrm{CHCl}_{3}$. Bulletin of the Chemical Society of Japan, 62, 1468-1471. http://dx.doi.org/10.1246/bcsj.62.1468

[20] Izatt, R.M., Terry, R.E., Haymore, B.L., Hansen, L.D., Dalley, N.K., Avondet, A.G. and Christensen, J.J. (1976) Calorimetric Titration Study of the Interaction of Several Uni- and Bivalent Cations with 15-crown-5, 18-crown-6, and Two Isomers of Dicyclohexo-18-crown-6 in Aqueous Solution at $25^{\circ} \mathrm{C}$ and $\mu=0.1$. Journal of the American Chemical Society, 98, 7620-7626. http://dx.doi.org/10.1021/ja00440a028

[21] Iwachido, T., Minami, M., Sadakane, A. and Tôei, K. (1977) The Coextraction of Water into Nitrobenzene with Alkaline Earth Metal 2,2',4,4',6,6'-Hexanitrodiphenylaminats in the Presence of the Crown Ethers. Chemistry Letters, 6, 1511-1514. http://dx.doi.org/10.1246/cl.1977.1511

[22] Kusakabe, S. and Arai, M. (1996) Solvent Extraction of Several Anions with Tetrabutylammonium Ion into 1,2-Dichloroethane and Hydration of Anions in the Organic Phase. Bulletin of the Chemical Society of Japan, 69, 581-588. http://dx.doi.org/10.1246/bcsj.69.581

[23] Katsuta, S., Wakabayashi, H., Tamaru, M., Kudo, Y. and Takeda, Y. (2007) Tetraalkylammonium Picrates in the Dichloromethane-Water System: Ion-Pair Formation and Liquid-Liquid Distribution of Free Ions and Ion Pairs. Journal of Solution Chemistry, 36, 531-547. http://dx.doi.org/10.1007/s10953-007-9121-x

[24] Katsuta, S. (2013) Distribution Behavior of Neutral and Anionic Compounds in Ionic Liquid/Water Biphase Systems. Bunseki Kagaku (Analytical Chemistry), 62, 297-315. (In Japanese)

[25] Katsuta, S., Nakamura, K., Kudo, Y. and Takeda, Y. (2012) Mechanisms of Rules of Anion Partition into Ionic Liquids: Phenolate Ions in Ionic Liquid/Water Biphasic Systems. Journal of Physical Chemistry B, 116, 852-859. http://dx.doi.org/10.1021/jp210444n

[26] Camagong, C.T. and Honjo, T. (2001) Separation of Gold (III) as Its Ion-Pair Complex with 18-Crown-6 from Hydrochloric Acid Media by Means of Solvent Extraction. Analytical Sciences, 17, i725-i728. [Proceedings of IUPAC International Congress on Analytical Sciences 2001 (ICAS 2001)]

[27] Dernini, S., Scrugli, A., Palmas, S. and Polcaro, A.M. (1996) Competitive Extraction of Pb ${ }^{2+}$ by Dicyclohexano-18crown-6 from Heavy Metal Aqueous Solutions. Journal of Chemical \& Engineering Data, 41, 1388-1391. http://dx.doi.org/10.1021/je9601523

[28] Mohapatra, P.K. and Manchanda, V.K. (1996) Ion-Pair Extraction of Tetravalent Plutonium from Hydrochloric Acid Medium Using Crown Ethers. Journal of Inclusion Phenomena and Molecular Recognition in Chemistry, 25, 257-265. http://dx.doi.org/10.1007/BF01044996

[29] Yoshida, Y., Yoshida, Z., Aoyagai, H., Kitatsuji, Y., Uehara, A. and Kihara, S. (2002) Evaluation of Gibbs Free Energy for the Transfer of a Highly Hydrophilic Ion from an Acidic Aqueous Solution to an Organic Solution Based on Ion 
Pair Extraction. Analytica Chimica Acta, 452, 149-161. http://dx.doi.org/10.1016/S0003-2670(01)01436-2

[30] Markin, V.S. and Volkov, A.G. (1989) The Gibbs Free Energy of Ion Transfer between Two Immiscible Liquids. Electrochimica Acta, 34, 93-107. http://dx.doi.org/10.1016/0013-4686(89)87072-0

[31] Kudo, Y., Usami, J., Katsuta, S. and Takeda, Y. (2004) Solvent Extraction of Silver Picrate by 3m-crown- $m$ Ethers $(m=5,6)$ and Its Mono-Benzo-Derivative from Water into Benzene or Chloroform: Elucidation of an Extraction Equilibrium Using Component Equilibrium Constants. Talanta, 62, 701-706. http://dx.doi.org/10.1016/j.talanta.2003.09.022

\section{Appendix I}

The basic extraction model [1] [3] [31] for the case (i) is as follows.

$$
\begin{gathered}
\left.\mathrm{M}^{+}+\mathrm{L} \rightleftharpoons \mathrm{ML}^{+} \text {(corresponding equilibrium constant is } K_{\mathrm{ML}}\right), \\
\mathrm{ML}^{+}+\mathrm{A}^{-} \rightleftharpoons \operatorname{MLA}\left(K_{1}\right), \\
\mathrm{MLA} \rightleftharpoons \mathrm{MLA}_{\mathrm{o}}\left(K_{\mathrm{D}, \mathrm{MLA}}\right), \\
\mathrm{MLA}_{\mathrm{o}} \rightleftharpoons \mathrm{ML}_{\mathrm{o}}^{+}+\mathrm{A}_{\mathrm{o}}^{-}\left(K_{1, \mathrm{org}}^{-1}\right), \\
\mathrm{ML}_{\mathrm{o}}^{+} \rightleftharpoons \mathrm{M}_{\mathrm{o}}^{+}+\mathrm{L}_{\mathrm{o}}\left(K_{\mathrm{ML}, \mathrm{org}}^{-1}\right)
\end{gathered}
$$

and

$$
\mathrm{M}^{+}+\mathrm{A}^{-} \rightleftharpoons \mathrm{MA}\left(K_{\mathrm{MA}}\right) \text {. }
$$

Consequently, these component equilibria yield those of $\mathrm{M}^{+} \rightleftharpoons \mathrm{M}_{\mathrm{o}}^{+}\left(K_{\mathrm{D}, \mathrm{M}}\right), \mathrm{ML}^{+} \rightleftharpoons \mathrm{ML}_{\mathrm{o}}^{+}\left(K_{\mathrm{D}, \mathrm{ML}}\right)$, $\mathrm{L} \rightleftharpoons \mathrm{L}_{\mathrm{o}} \quad\left(K_{\mathrm{D}, \mathrm{L}}\right)$ and $\mathrm{A}^{-} \rightleftharpoons \mathrm{A}_{\mathrm{o}}^{-}\left(K_{\mathrm{D}, \mathrm{A}}\right)$. An extraction of HPic, $\mathrm{H}^{+}+\mathrm{Pic}^{-} \rightleftharpoons \mathrm{HPic}_{\mathrm{o}}\left(K_{\mathrm{ex}, \mathrm{HPic}}\right)$, was added in the $\left[\mathrm{Pic}^{-}\right]$calculation. The distribution [31] of $\operatorname{AgPic}(=\mathrm{MA})$ into the DCE phase was neglected in this study; its constant was not available from references.

The case (ii) [2] [6] [7] was

$$
\begin{gathered}
\mathrm{M}^{2+}+\mathrm{L} \rightleftharpoons \mathrm{ML}^{2+}\left(K_{\mathrm{ML}}\right), \\
\mathrm{ML}^{2+}+\mathrm{A}^{-} \rightleftharpoons \mathrm{MLA}^{+} \quad\left(K_{1}\right), \\
\mathrm{MLA}^{+}+\mathrm{A}^{-} \rightleftharpoons \mathrm{MLA}_{2} \quad\left(K_{2}\right), \\
\mathrm{MLA}_{2} \rightleftharpoons \mathrm{MLA}_{2, \mathrm{o}} \quad\left(K_{\mathrm{D}, \mathrm{MLA} 2}\right), \\
\mathrm{MLA}_{2, \mathrm{o}} \rightleftharpoons \mathrm{MLA}_{\mathrm{o}}^{+}+\mathrm{A}_{\mathrm{o}}^{-} \quad\left(K_{2, \mathrm{org}}^{-1}\right), \\
\mathrm{MLA}_{\mathrm{o}}^{+} \rightleftharpoons \mathrm{ML}_{\mathrm{o}}^{2+}+\mathrm{A}_{\mathrm{o}}^{-}\left(K_{1, \mathrm{org}}^{-1}\right), \\
\mathrm{ML}_{\mathrm{o}}^{2+} \rightleftharpoons \mathrm{M}_{\mathrm{o}}^{2+}+\mathrm{L}_{\mathrm{o}} \quad\left(K_{\mathrm{ML}, \mathrm{org}}^{-1}\right)
\end{gathered}
$$

and

$$
\mathrm{M}^{2+}+\mathrm{A}^{-} \rightleftharpoons \mathrm{MA}^{+}\left(K_{\mathrm{MA}+}\right),
$$

where the distribution of $\mathrm{MPic}^{+}\left(=\mathrm{MA}^{+}\right)$into the NB phase was neglected; their constants were not available from references. Similarly, some equilibria, such as $\mathrm{M}^{2+} \rightleftharpoons \mathrm{M}_{\mathrm{o}}^{2+}\left(K_{\mathrm{D}, \mathrm{M}}\right), \mathrm{ML}^{2+} \rightleftharpoons \mathrm{ML}_{\mathrm{o}}^{2+}\left(K_{\mathrm{D}, \mathrm{ML}}\right)$ and $\mathrm{L} \rightleftharpoons \mathrm{L}_{\mathrm{o}}$, can be given from the above component equilibria and the $K_{\mathrm{ex}, \mathrm{HPic}}$ value was included in the calculation.

The both models, (i) \& (ii), do not contain supporting electrolytes in the o phases. This point is a large difference from corresponding electrochemical measurements [29] [30]. 


\section{Appendix II}

The $K_{\mathrm{D}, \mathrm{A}}$ values have been determined extraction-experimentally using the following equations [1]-[3] [6] [7].

$$
\begin{gathered}
\log K_{\mathrm{ex}}^{\mathrm{mix}}=\log \left(\sum\left[\mathrm{MLA}_{N}^{(z-N)+}\right]_{0} /\left[\mathrm{M}^{z+}\right][\mathrm{L}]_{0}\left[\mathrm{~A}^{-}\right]^{z}\right) \\
\approx \log \left\{K_{\mathrm{ex}}+K_{\mathrm{D}, \mathrm{A}} /\left(\left[\mathrm{M}^{z+}\right][\mathrm{L}]_{\mathrm{o}}\left[\mathrm{A}^{-}\right]^{z-1}\right)\right\}
\end{gathered}
$$

for $N=0,1$ at $Z=1$ (the case of $\mathrm{M}^{+}$) or for $N=1,2$ at $Z=2$ (that of $\mathrm{M}^{2+}$ ). Hence, the plots of $\log K_{\mathrm{ex}}^{\operatorname{mix}}$ versus $-\log \left(\left[\mathrm{M}^{+}\right][\mathrm{L}]_{0}\right)$ [1] [3] and versus $-\log \left(\left[\mathrm{M}^{2+}\right][\mathrm{L}]_{0}\left[\mathrm{~A}^{-}\right]\right)$[2] [6] [7] based on Equation (A16) give the $K_{\mathrm{D}, \mathrm{A}}$ value with the $K_{\mathrm{ex}}$ ones for the MA- and $\mathrm{MA}_{2}-\mathrm{L}$ extraction systems, respectively. Here, the $\sum\left[\mathrm{MLA}_{N}^{(z-N)+}\right]_{0}$ values are determined by AAS measurements and then the $\left[\mathrm{M}^{2+}\right],[\mathrm{L}]_{0}$ and $\left[\mathrm{A}^{-}\right]$values are

calculated by a successive approximation [1]-[3] [6] [7]. The following mass-balance equations have been employed for the approximation: $\left[\mathrm{ML}^{+}\right]_{0} \approx\left[\mathrm{A}^{-}\right]_{0}[1][3]$ against Equation (1) and $\left[\mathrm{MLA}^{+}\right]_{0} \approx\left[\mathrm{A}^{-}\right]_{0}[2]$

[6] [7] against Equation (7) (see the Section 3.1).

Similarly, the $K_{\mathrm{ex} \pm}$ values have been evaluated from the other arranged form of Equation (A15),

$$
\log K_{\mathrm{ex}}^{\mathrm{mix}} \approx \log \left\{K_{\mathrm{ex}}+\left(K_{\mathrm{ex} \pm} /\left[\mathrm{M}^{z+}\right][\mathrm{L}]_{0}\left[\mathrm{~A}^{-}\right]^{z}\right)^{1 / 2}\right\}
$$

for $N=0,1$ at $z=1$ or for 1,2 at 2 [3] [7]. 